\title{
Temporal Spillovers in Land Conservation
}

\author{
Sarah Jacobson ${ }^{*}$ \\ Department of Economics \\ Williams College \\ 24 Hopkins Hall Dr. \\ Williamstown, MA 01267 \\ Sarah.A.Jacobson@williams.edu \\ 413-597-4766
}

August 2012

\begin{abstract}
:
Temporal spillovers occur when a conservation program preserves land during a contract period but shifts non-conservation use to later-or, worse, induces more intensive use later. This may happen when conservation improves land so that returns to other uses are increased. I explore temporal spillovers of the Conservation Reserve Program (CRP). I use a pre-analysis sample specification step to choose counterfactual land most like the CRP land. I find that CRP causes some land to be $22-27 \%$ more likely to be farmed, potentially offsetting some environmental benefits. However, farmed ex-CRP land is slightly more likely to use a conservation practice.
\end{abstract}

Keywords: temporal spillovers, Conservation Reserve Program, land use, environmental policy, farm policy

JEL Classification: Q15, Q18, Q24, Q58, R14

\footnotetext{
* I am very grateful to Spencer Banzhaf, Paul Ferraro, and Michael Roberts for extremely helpful input on earlier drafts, and to Ruben Lubowski for sharing data. I also thank the following for their useful comments: Ragan Petrie, James Cox, Vjollca Sadiraj, Doug Gollin, Jason Delaney, and participants at various seminars and workshops.
} 
Payment for environmental services programs have become popular conservation tools because these incentive-based methods are believed to have desirable properties. However, it is important to understand the unintended consequences such programs can have. Some unintended consequences can occur through spillovers in which environmentally harmful uses are shifted. These shifts can offset some of the environmental benefits of these conservation programs. Spatial "slippage" in land conservation occurs when subsidized land conservation causes land not in the program to be brought into use - that is, the enrollment of land reduces conservation of non-enrolled land. ${ }^{1}$ Temporal spillovers can occur in the context of a temporary conservation contract like those used in some land conservation programs. If land that enters such contracts simply shifts intensive use to a post-contract period, some environmental benefits may be reduced. This reduction is even greater if participation in the program causes an increase later intensive use, as may be the case if conserved land becomes improved in quality. These temporal spillovers matter because if we study a program's impact by examining outcomes that occur only during a contract period, we may overstate the program's benefits.

In this paper, I study temporal spillovers. Temporal spillovers are difficult to identify for many of the same reasons that it is difficult to identify the direct effects of payment for environmental services programs: unobservable heterogeneity that drives the entrance into the program and is correlated with outcomes. Further, the conservation program studied must be large and long-lived, and we must be able to observe outcomes after the end of temporary contracts. I demonstrate the concept in the context of the Conservation Reserve Program (CRP), the United States' largest conservation program, in a nationwide land use analysis. Paying careful attention to the specification of counterfactual land, I ask: how did the CRP experience of

\footnotetext{
${ }^{1}$ Spatial "slippage" in the context of the Conservation Reserve Program is discussed in Wu (2000) and a series of related articles. Here, land is pressed into farming because CRP enrollment reduces the current stock of cropland.
} 
subsidized conservation affect the land's later use? In particular, does a land parcel's time in the CRP increase or decrease environmentally friendly land use in the long run? By comparing exCRP land to the most comparable non-CRP land, I find that the CRP causes at least some parcels to be $22-27 \%$ more likely to be farmed after exiting the contract. This is evidence of a temporal spillover that reduces the program's environmental benefits. On the other hand, CRP land is slightly more likely to use conservation farming practices.

Since its creation with the 1985 Food Security Act, the CRP has sought to achieve a variety of conservation, agricultural, and socioeconomic goals. Through the program, each year since 1990 has seen 30-35 million acres of US farmland enrolled in voluntary conservation contracts. Farmers who wish to join the program "bid" by specifying a parcel of agricultural land, proposing an annual rental payment amount they'd like to receive, and choosing a conservation practice to implement. These contracts bind the farmer to abstain from cultivation for 10-15 years and to undertake conservation measures, including planting an approved cover crop. The program provides annual rental payments negotiated for each enrolled parcel and costshares to cover up to $50 \%$ of the costs of conservation activities. When a contract expires, the landowner may apply for a new contract or may put the land to some other use.

A major goal of the program is to reduce erosion through both the reduced intensity of use that results from a "break" in cultivation and the additionally soil-rebuilding properties of the conservation cover crops used in the program. The program also has broader environmental and habitat-related goals, as reflected in the program's evolving eligibility rules. It is clear that gains are made on land enrolled in the program; erodibility is demonstrably reduced (Uri, 2001) and the benefits of these improvements have been considerable (Feather et al., 1999). However, this land improvement could have unintended consequences. Better-quality land is more 
agriculturally productive. (Another goal of the CRP is to improve country's agricultural productivity over the long term.) If returns to farming are increased, the land will be more likely to be farmed. In this way, CRP may not simply shift intensive use to later years but actually increase intensity of later use. CRP participation may thus make land more likely to be cultivated later than it would have been had that land never entered the CRP. This is the mechanism by which temporal spillovers are most likely to occur.

This effect could be reinforced by an interaction between the CRP and other agricultural payments. As discussed in Young et al. (2005), land that is enrolled in CRP and then taken out of the program can be immediately added back into a farm's crop acreage bases, which is often not true for land that was idled otherwise. These base acres are used to calculate benefits such as direct and counter-cyclical payments. Eligibility for payments for these acres is regained in a way that would be impossible if the land was simply left idle. A farmer may wish to temporarily stop farming marginal land, for example, when crop prices are low; to do so may reduce future commodity program payments unless that land is entered into the CRP. These rules regarding CRP and base acreage encourage farmers to convert CRP land (more than other idled marginal land) back into cultivation.

In both of these ways, the CRP may cause an increased likelihood of farming on land that exits the program. Farmers, knowing these channels for increased profits, may enroll marginal land with the aim of being paid to improve that land while in the program and continuing or increasing cultivation after completing a contract. This may reduce the net environmental benefits produced by the program and increase the economic surplus reaped by farmers. On the other hand, some previous research that indirectly addresses this issue suggests that CRP experience may cause land to continue to be conserved later. This could happen if farmers' 
preferences for conservation or stewardship overwhelm their profit motive (e.g. Chouinard et al., 2008; Sheeder and Lynne, 2011; Wallace and Clearfield, 1997) and if experience in conservation strengthens that preference. This would be a positive temporal spillover effect.

Temporal spillovers of payments for environmental services programs have not yet received much attention. In the context of the CRP, there have long been efforts to understand what happens to land when it exits the program, but no causal attribution of these results to CRP experience. Early surveys (for example, Cooper and Osborn, 1998; Johnson et al., 1997) of the uses farmers expected to undertake later on land currently in the CRP showed that farmers expected to base their decisions on market prices. General equilibrium analyses use past land use transition patterns to predict future land use transitions. Several such studies have estimated how much CRP land would return into farming if the program did not exist or were eliminated, and estimates range widely: 57\% in De La Torre Ugarte et al. (1995), 37\% in De La Torre Ugarte and Hellwinckel (2006), and 88\% in calculations from Lubowski, Plantinga, and Stavins (2008). Roberts and Lubowski (2007) look carefully at selectivity in CRP exit to estimate that 58\% of CRP land would enter farming if the program were eliminated, and conclude that a large segment of ex-CRP land persists in conservation. However, none of these results can be compared to a counterfactual in which the land had never entered the CRP, since CRP land is likely to be quite different from non-CRP land. That is, existing results cannot tell us whether the CRP causes land to be less likely to be farmed after exiting the program.

The difficulty in identifying temporal spillovers in this case is the difficulty in finding appropriate counterfactual plots of land to which to compare land leaving CRP contracts. The desired counterfactual land is otherwise identical to CRP land but did not enter the program (allowing the program and its general equilibrium effects to still exist). Observable differences 
between land that enters the program and land that does not can be controlled for in analysis; however, unobservable differences in land quality may be large. If unobservable land quality drives agricultural productivity, it will be strongly correlated with both program enrollment and later intensity of use. Naïve analyses ignoring this will be subject to bias.

I compare ex-CRP land to land that has not been in the program to ask: did CRP participation cause changes in later land use of enrolled parcels (compared to the use they would have entered had they never been in CRP)? That is, does the CRP have temporal spillovers?

This paper contributes to the literature in a number of ways. I introduce the concept of a temporal spillover and demonstrate its potential importance whenever conservation alters land quality. I attribute causality to CRP experience by using plausible counterfactual (non-CRP) land parcels. My methodology is innovative in the use of a sample specification step that trims the treatment (CRP) and control (non-CRP) groups to the most comparable units. I also perform a multinomial logit analysis, which more thoroughly explores the land use decision. Finally, I study adoption of conservation practices on land that exits CRP and is later farmed.

I find that a naïve analysis without careful specification of counterfactual land shows that ex-CRP land is farmed at a lower rate than other parcels. However, when compared with the most appropriate counterfactual land, ex-CRP land is $22-27 \%$ more likely to be farmed than nonCRP land. Because this land is very much like the ex-CRP group, I can infer that the increase in cultivation is caused by CRP participation. This result is novel in the literature but is not unexpected since the land should have improved while in the program. Thus, the CRP's longterm effects work against the environmental goals of the program (although they may comport with the program's agricultural efficiency goals). I also show that cultivated ex-CRP land is more 
likely than similar land to adopt a conservation practice such as contour farming. However, I cannot infer whether the increased conservation practice use is caused by CRP participation.

This paper proceeds as follows. In the next section, I discuss a model of land use choice. Next, I describe the methods I will use to address the research questions. In the following section, I introduce the data. I give special attention to the sample specification step that will be used in the analysis. I present results in the following section. In the final section I conclude.

\section{Theory}

I assume that land use is driven by the value of each use for each land parcel. Each land parcel has inherent characteristics, some static $\left(s_{i}\right)$ and some varying with time $\left(x_{i t}\right)$. Parcel $i$ 's return (or quasi-rent) at time $t$ to use $a \in A$, where $A$ is the set of all possible land uses, is a function of that parcel's characteristics and local market parameters $\left(p_{i t}\right)$. I focus on a single one-time land use transition where likelihood of transition is determined by these factors, some of which being influenced by past land use (and thus past transitions).

Some land characteristics that are affect quasi-rents are observable. Static elements of this type include parcel location. Dynamic elements of this type include observable land quality elements and local demographics. I assume that market prices are observable, although the quasirents for each land use for a given parcel will depend on interactions between these exogenous prices and the parcel's characteristics. However, unobservable parcel characteristics will also inevitably affect land use. Let $z_{i t}$ be an unobservable element of land quality of parcel $i$ in time $t$ that is correlated with the returns to farming and that ranges from 0 to 1.

The parcel-specific return from each land use is:

$\pi_{a i t}=\pi\left(a \mid s_{i}, x_{i t}, p_{i t}, z_{i t}\right)$ 
Then observed land use is:

$a^{*}=\arg \max _{a \in A} \pi\left(a \mid s_{i}, x_{i t}, p_{i t}, z_{i t}\right)$

It would also be possible to use another variable, say $\sigma_{i t}$, to represent unobservable landowner preferences. Such a variable could affect the quasi-rents to a conservation use. For simplicity I do not include this variable, but I will revisit this idea below.

There are several land uses of particular interest. Cultivated cropland is environmentally intensive but potentially lucrative for high-quality land. I will designate this use as $a=a_{f}$. Noncultivated cropland, land use $a=a_{n}$, which is often used to produce hay, is less intensive and less lucrative. Conservation, $a=a_{c}$, provides fixed payments and improves the land (makes some elements of $x_{i t+1}$ and $z_{i t+1}$ increase). I will use CRP as the example of a conservation program, although this logic applies to other similar programs.

Since a parcel will enter into the use with the highest profit, the likelihood that land parcel $i$ is in cultivation at time $t$ is:

$\operatorname{Pr}\left(\pi_{f i t} \geq \pi_{\text {nit }} \& \pi_{\text {fit }} \geq \pi_{\text {cit }}\right)$

We can then say that some function $\phi$ determines the likelihood of farming, driven by the land and market characteristics.

$\operatorname{Pr}\left(a_{i t}=a_{f}\right)=\phi\left(s_{i}, x_{i t}, p_{i t}, z_{i t}\right)$

We assume in particular that $\frac{\partial \phi}{\partial z_{i t}}>0$.

Similar equations would predict the probability that a land parcel enters any other use. Of the three uses of interest, farming will tend to have the highest returns for land that is fairly fertile. Land that is of lower quality will be less productive and thus less profitable as farmland, 
so landowners would have to decide between non-cultivation and conservation. This outcome may not be entirely driven by the landowners' returns, however: conservation programs like CRP limit enrollment with acreage limits, bid caps, and eligibility criteria. A parcel of land that is observed in non-cultivation may therefore have expected higher profits from conservation but might have failed to enter the program (e.g. may have applied and been rejected). In practice, in the first decade of the CRP, bid rejections were often caused by requests for rental payments that were too high. ${ }^{2}$

Recall that $z_{i t}$ is unobservable and is correlated with agricultural productivity. Two land parcels with similar observable elements $\left(s_{i}, x_{i t}, p_{i t}\right)$ and different land uses should have different levels of $z_{i t}$. That is, from observed land use we can draw inferences abut unobservable land quality. Suppose $z_{i t}$ varies within a range as demonstrated in Figure 1. Very high quality land $(\bar{z}<z \leq 1)$ is very productive farmland and will always be farmed. Very low quality land $(0 \leq z<\underline{z})$ is never productive enough to be farmed. Marginal farmland $(\underline{z} \leq z \leq \bar{z})$ may fall in and out of farming as market conditions vary. Some marginal farmland that leaves farming may enter conservation programs. ${ }^{3}$ Other marginal farmland may simply remain uncultivated.

However, it should be the case that land that was marginal enough to enter conservation has a $z_{i t}$ value most like land that occasionally exits farming.

High quality land has a higher average value of $z$ than does marginal land, including the land that is conserved. Since this difference is unobservable, land use regressions that ignore this

\footnotetext{
${ }^{2}$ Eligibility is now based on an "Environmental Benefits Index" (EBI), and the payment requested is only part of that. However, personal correspondence with USDA staff reveals that those first waves during the program's rampup generally did not have high rejection rates, and that rejections in those years were largely caused by high bids. In these early waves, the EBI did not exist. Eligibility was determined by erodibility index. The program's bid cap for each county was kept private to reduce strategic behavior (Shoemaker, 1989). If the bidding process were incentive compatible, bids would represent opportunity costs so a rejected bid would imply that conservation did not provide the highest return. If farmers know bid caps the process cannot be incentive compatible.

${ }^{3} \mathrm{CRP}$ and similar programs only enroll land that is currently cultivated.
} 
selective conservation will find that conserved (e.g., CRP-enrolled) land is later farmed at a lower rate. This difference, caused by unobservable differences in land quality, will mask any changes in later land use that are caused by conservation participation. Such a regression would be biased in favor of finding conserved land less likely to be cultivated later.

To eliminate this bias, conserved land must be compared to land with $z$-values in the same range. If conserved land is compared to marginal-quality land that enters temporary noncultivation, the average value and distribution of $z$ may be similar across the two groups of land and therefore differences in later land use may be attributable to program participation.

How may changes in later land use be caused by conservation program participation? The best land use of a parcel may change over time. Changes in market characteristics, observable land characteristics, and local demographics will drive changes in quasi-rents that could change the optimal land use. However, unobservable land quality $z_{i t}$ could also change over time. Specifically, conservation improves soil quality: CRP participation has been shown to reduce erodibility (e.g., Uri, 2001), and this should increase the return to cultivation. Thus marginal land that enters a program like CRP with a low $z_{i t}$ may emerge from the program with a higher $z_{i+1 t}$ and thus be more likely to be farmed. We could model this in a simple way by saying that $z_{i t}$ has some persistent component (i.e., depends in part on $z_{i t-1}$ ) but also depends on participation in the conservation program in the last periods, $C_{i t-1}$.

$$
\operatorname{Pr}\left(a_{i t}=a_{f}\right)=\phi\left(s_{i}, x_{i t}, p_{i t}, z_{i t}\left(C_{i t-1}, z_{i t-1}\right)\right)
$$

Here again, $\frac{\partial \phi}{\partial z_{i t}}>0$. If $\frac{\partial z_{i t}}{\partial C_{i t-1}}>0$, past conservation program participation increases unobservable quality, so it should be the case that $\frac{\partial \phi}{\partial C_{i t-1>0}}$. This is the case of a temporal spillover: a case when past conservation causes increased probability of farming later. 
In this way, conservation programs like CRP may work like a subsidized fallow program. Land also improves while it is simply non-cultivated, but more improvements occur under CRP because the government shares up to half of the costs of planting a conservation cover crop. Also, CRP contracts are 10-15 years long, longer than most standard fallow cycles.

A transition from into farming for an ex-CRP parcel as compared to other idle land of identical quality may also lend a greater profit from cultivation because it may yield higher commodity program payments, as discussed above, through an increase in base acreage. Thus even if plots of CRP and non-CRP land have identical $s_{i}, x_{i t}$, and $z_{i t}$ variables and operate in the same markets, CRP land may effectively have larger cultivation-related elements of $p_{i t}$ and as a result may have a greater likelihood of converting to farming.

The argument I have made for differences and changes in unobservable land quality $z_{i t}$ could also be made for $\sigma_{i t}$, an unobservable variable representing a taste for stewardship. Landowners with little taste for stewardship may tend to keep farmable land in cultivation, but landowners with moderate taste for stewardship may take breaks from cultivation on sensitive land or may enroll sensitive land in a conservation program. If experiencing conservation in period $t$ causes a landowner to have an increased taste for stewardship then CRP participation could cause decreased later cultivation by causing $\sigma_{i t+l}$ and therefore $\pi_{c i t+l}$ to increase.

These changes in land use may be rendered harder to detect by the presence of transition costs, particularly costs of entering cultivation. To cause a land use change, the difference in profits between the current use and the preferred land use must be large enough to overcome any transition costs. Observed land use transitions will actually understate changes in quasi-rents caused by program participation. 


\section{Methods}

The question of the CRP's effect on later land use requires a comparison of the land use on a parcel that has been in the program to the use it would have been in had that parcel not been in the program. To identify this effect, I compare end-of-period (1997) use on land that has been in the CRP to land that has not been in the CRP and see which is more likely to enter cultivation (or other land uses). However, any causal effect of the CRP may be masked if unobservable land quality $z_{i t}$ drives both land use. I perform a sample selection step to choose the best set of counterfactual land so that causality can be attributed to CRP participation. Conceptually, this is a population-level process much like the observation-level process of matching: the most comparable treatment and control group are selected based on observables to reduce bias. This sample specification step is a selection process targeting the CRP and non-CRP parcels that are most comparable based on characteristics inferred from their patterns of land use. Specifically, I infer a parcel's $z_{i t}$ from the parcel's land use and use that to identify comparable land.

The first issue in sample specification is that the majority of CRP land is locked into a conservation contract at any given time, and there is usually a penalty for early exit. This is, in effect, a large barrier to transition. It is sensible to only examine CRP parcels that have a potential land use decision to make. I consider two such subsamples of CRP land. First, a subsample I call CRP-Eligible includes all land that was in the CRP during the time of interest but is probably eligible to exit. Since contract data are not publicly available, I cannot determine actual eligibility, but I can infer a likely contract end date from the observable signup wave in which the parcel entered the program (assuming a 10-year contract).

While contracts should largely dictate program exit, land is sometimes administratively allowed to leave the CRP before contract expiration. In addition, in the time period of interest the 
USDA automatically granted one-year extensions to many farmers whose contracts were expired because this was the first major round of expirations. Because of these complications, CRPEligible is an imperfect group. I specify a separate and perhaps preferable sample called CRPExit, comprising only land that actually was observed exiting the program. This land verifiably had a post-CRP land use decision to make. Of course, inferences made about this land must be tempered by concerns about selective exit: landowners may choose to take land out of the program for economic reasons. For this reason, whenever I use this sample I note that the results apply to "some" parcels in the CRP, that is, that the estimates are local.

The more nuanced issue in sample specification is unobservable land quality of counterfactual (non-CRP) land. I specify a large subsample called Control-All to include all initially-cultivated land. However, as discussed in the Theory section, this land will include a range of land qualities $(\underline{z} \leq z<1)$. Much of this subsample (land with $\bar{z}<z \leq 1)$ is likely to stay in cultivation. This land is a poor counterfactual for CRP land. Analysis using Control-All will be biased toward finding CRP land less likely to be cultivated.

For this reason, I specify another subsample of non-CRP land: Control-Unfarmed. This land is a good counterfactual set for CRP land because, like CRP land, it should be marginal land in the sense of having a moderate level of $z(\underline{z} \leq z \leq \bar{z})$. I can infer this moderate level of $z$ from the uses the land has been put to over the years. Marginal farmland may be taken in and out of farming over time as market conditions vary. Control-Unfarmed includes land that started out being cultivated at the same time that the CRP land was cultivated. The subsample is restricted, however, to land that was not cultivated for some intervening period. Not only should ControlUnfarmed have a level of $z$ similar to that of CRP land, but this land also faces transition costs to re-enter cultivation just as CRP land would. These transition costs would not be present for land 
the continued to be cultivation, and this could be another source of bias when CRP land is compared to Control-All.

In the analysis that follows, I compare the tendency to enter into cultivated cropping, to enter into various other uses, and (for farmed land) to use conservation practices between CRP land and non-CRP land using the categories defined above. I do this using OLS, logit, and probit regressions. I argue that the comparison between CRP-Exit and Control-Unfarmed land is the best measure of the effects that CRP has on at least some parcels of land.

The sample specification step and the use of several different models will reduce the potential bias caused by observable and unobservable differences between CRP and non-CRP land. However, some sources of bias may persist.

First, Control-Unfarmed land may be lower quality (lower $z$ ) than ex-CRP land because Control-Unfarmed was willing to retire from farming without a subsidy while some CRP land probably would not have retired without being paid. On the other hand, some Control-Unfarmed land may be higher quality (higher $z$ ) because it left farming but did not choose to enter CRP. (I cannot identify which land applied to CRP and was rejected and which did not apply.) These farmers may have stayed out of CRP to retain the option of farming. There is no way to know which of these countervailing forces is of greater importance in this data set.

Second, some Control-Unfarmed land may be in fallow cycles. The data set I use tries to classify land that is in a fallow cycle as cultivated cropland. Land classified as non-cultivated cropland (which is mostly hay) or pastureland is verified to have not been cultivated cropland for the last three years. However, if land is in a fallow cycle of five years or longer, it may be misclassified as pasture or non-cultivated cropland, in which case I would include it in ControlUnfarmed. Parcels that exit CRP may begin farming immediately because they will have just 
emerged from a 10-year fallow period (their CRP tenure), but only some non-CRP parcels in long fallow cycles will be ready to farm. This may make Control-Unfarmed appear less likely to be farmed as compared to ex-CRP land. On the other hand, transitions into farming take time. While non-CRP land can move into farming in any year, CRP land can only transition after contracts end. Thus, if land use is observed only every few years then ex-CRP land transitions may be under-recorded relative to non-CRP land transitions, making Control-Unfarmed land seem more likely to be farmed. Again, it is impossible to know which effect might dominate.

Because of these factors, Control-Unfarmed land may have unobservable land quality $z$ slightly better or slightly worse than CRP land. However, the resulting bias should be small. Further, Control-Unfarmed is still the best possible counterfactual group for CRP land and thus my results will be less biased than results of analysis that fails to account for these issues. In the Results section, I will discuss robustness checks using alternative specifications of the counterfactual group.

\section{Data and Summary Statistics}

I use data from a large nationwide land survey to collect land characteristics at the parcel level. I supplement those data with county-level estimates of the returns to various land uses. CRP contract information is sensitive and therefore is not distributed at a level of detail that is useful for parcel-level analysis, so will not enter into this analysis.

First, parcel-level data were obtained from the USDA's National Resource Inventory (NRI; see US Department of Agriculture, 2001). The NRI is a panel survey of over 800,000 land parcel samples throughout the country. It provides data for $1982,1987,1992$, and $1997 .{ }^{4}$ The NRI is a stratified survey, and the analysis that follows takes into account the NRI's sampling

\footnotetext{
${ }^{4}$ The NRI has been conducted since 1997, but the USDA does not make these later years' data available.
} 
structure. The unit of observation is essentially a sampled parcel, but each sampled parcel has an expansion factor defining the land area this observation represents. These expansion factors range from 1 to 495 and average 15.730 acres per point in the NRI overall. ${ }^{5}$ Parcel location information is available but limited in precision because the NRI data are designed to render precise sample location identification impossible. It is not possible to obtain information about ownership of the land sampled, e.g., which land samples are owned by the same person. I restrict my analysis to the forty-eight contiguous states. Variables reflecting essential land quality data are not recorded for land that is urban, transportation, federal, or water so I exclude parcels that entered one of these land uses in 1997. This exclusion is particularly acceptable because this land's use may be idiosyncratic. ${ }^{6}$ Variables reflecting other land quality data (erodibility and slope) are not available for these land uses or for pasture, range, forest, and other rural; since pasture is a relatively important use in this setting, my analysis will exclude those variables.

The timeline of data samples as they relate to important years for the CRP is shown in Figure 2. The focus of this analysis is on land that exited CRP by the 1997 NRI sample, and that includes the first wave of CRP contract expirations. Figure 2 also shows the land use patterns that defines each of the subsamples specified for the analysis.

The NRI land quality data of interest for this analysis are slope (Universal Soil Loss Equation (USLE) slope percent), erodibility index (defined as the maximum of wind and water erodibility values), land capability classification (US Department of Agriculture, 2009), and the prime farmland indicator (ibid.). Slope and erodibility are clearly important elements of land quality, with steeper-sloped and more erodible land being less agriculturally productive. Land capability classification is an indicator of a soil's ability to produce crops; I use an indicator

\footnotetext{
${ }^{5}$ Only 388 of the 266,992 NRI points represent more than 100 acres and only 83 more than 200 acres.

${ }^{6}$ Results hold for specifications excluding land classification (the characteristic available for the fewest uses) from the control variable set and including the land from these 1997 uses (available upon request).
} 
variable ("good land classification") for land with land capability classification of four or less. Land is identified as prime if it meets a set of criteria that should be conducive to agricultural productivity, including frequency of flooding, irrigation, water table, and wind erodibility. With regard to land use, I focus primarily on several of the NRI's broad use categories: cultivated cropland, non-cultivated cropland (about 95\% of which is hay), pasture, and CRP. Throughout this paper, cultivated cropland will be referred to as "farmed" land, and this is the high-intensity land use of interest in this study. This use includes all close and row crops.

The second source of data is a set of county-level proxies for the returns to various land uses. These data consist of 1996 rent levels and 1986-1996 changes in rent levels for various land use categories. These rent data are described in the appendix of Roberts and Lubowski (2007). These county-level proxies are only available for 1,600 counties, and the analysis considers only counties for which rent data are available. ${ }^{7}$

Table 1 shows the characteristics of land in subpopulations of interest. The first column shows all land that was cultivated in 1982, and the second column shows all land that was in CRP in 1992. As expected, CRP land is worse than the broader sample of originally-farmed land by all measures (less likely to be prime or have a good land classification, more erodible, and more sloped). CRP land also tends to stay in CRP at a very high rate, and farmed land tends to continue to be farmed at a high rate. Among the specified subsamples, Control-All (the general non-CRP land sample) has higher observable quality measures than all of the other groups, including Control-Unfarmed (the land that left farming but did not enter CRP). Both Control groups are of better quality than both CRP groups. CRP-Exit is of somewhat better quality by most measures than the CRP-Eligible group (for example, CRP-Exit is more likely to be prime,

\footnotetext{
${ }^{7}$ All NRI counties with CRP parcels have rent data; only non-CRP parcels are thus excluded. Summary statistics including parcels without rent data are similar to those presented here (available upon request).
} 
less erodible, and in an area with greater returns to cropping), which supports the intuition that some land leaves CRP specifically to be farmed. ${ }^{8}$ Control-Unfarmed is very slightly better than CRP-Exit on observable characteristics. Overall, the pattern of observable land quality characteristics across the land subsamples supports the notion that CRP and Control-Unfarmed are roughly similar marginal land while Control-All is of much higher quality.

Table 1 also shows that $61.7 \%$ of all land that was in the CRP in 1992 was part of an early signup wave, but only $82.1 \%$ of all land that exited CRP between 1992-1997 was in an early signup wave (probably because of contract releases that were granted at that time). Most (86.3\%) CRP-Eligible land stayed in CRP in 1997, and most Control-All land was farmed in 1992 $(92.1 \%)$ and 1997 (89.1\%). Finally, CRP-Exit land is unconditionally more likely to be farmed than the Control-Unfarmed sample. This result will continue to hold throughout the analyses.

\section{Results}

I study the relationship between CRP experience and land use outcome, both as a binary choice (cultivated or not) and as a multinomial choice. Here I can infer causality on the part of the CRP because I have matched parcels with similar observable and perhaps unobservable characteristics ( $\operatorname{similar} z$ ). I then examine conservation practice takeup, further restricting the subsamples to land that is farmed in 1997. There are competing reasons why ex-CRP land may adopt conservation practices at a higher rate, so I cannot infer causality for this result.

\section{Binary Land Use Outcome Results}

I begin with a simple binary choice model: the landowner chooses whether to put the land into "farming" (cultivated cropland) or into some other use. He makes his decision based on the

\footnotetext{
${ }^{8}$ Roberts and Lubowski (2007) find that land is more likely to exit CRP if it is planted in grass or legumes as cover, and also find that tendency to exit is correlated with rent proxies for several uses and with some interactions between land quality and rent proxies.
} 
quasi-rents for each use. I regress a dummy variable $f_{i t}$ representing whether a parcel was farmed in the period of interest on the observable variables: ${ }^{9}$

$$
f_{i t}=\psi\left(s_{i}, \mathbf{x}_{i t}, \mathbf{p}_{i t}\right)
$$

I start with a naïve analysis ignoring selection into CRP on unobservables to show the problems with that approach. This analysis uses all NRI observations for which county-level rent data are available. As shown in Table 2, in three different OLS (linear probability model) specifications, ${ }^{10}$ I use mutually exclusive dummies to compare 1997 use of CRP land to 1997 use of other land. Specification I uses dummies to indicate 1992 CRP participation and 1992 farming. This specification shows that land that was in the CRP in 1992 is less likely to be farmed in 1997 than land that was farmed in 1992 and even than land that was neither farmed nor CRP in 1992. ${ }^{11}$ These results are driven by the fact that much of the land farmed in 1992 was still farmed in 1997, and much of the land in CRP in 1992 was still in CRP in 1997.

Specification II in Table 2 replaces the CRP dummy with dummies to indicate early CRP signup and late CRP signup, since early enrollees are more likely to be eligible to exit. Results show the same trend. Specification III in Table 2 hints at the need for sample re-specification. Dummies are included to indicate CRP exit and CRP participation in 1992 without an exit. While CRP-NOEXIT has a negative coefficient, CRP-EXIT has a positive coefficient. This land is more likely to enter farming than the baseline group. The baseline group includes land that was neither farmed nor in CRP in 1992.

For a more nuanced result, I use the specified subsamples described in the Methods section. Results are shown in Table 3. The table shows the coefficient on (or the marginal effect

\footnotetext{
${ }^{9}$ As discussed above, slope and erodibility are not available for many land uses of interest, so the only observable land quality characteristics included in this and other analyses are the prime and good land classification indicators.

${ }^{10}$ Results are very similar for logit and probit specifications as well; results available upon request.

${ }^{11}$ An analogous matching analysis, shown in the Appendix, yields results similar to Specification I.
} 
of) the CRP dummy for OLS, logit, and probit regressions. Results from matching analysis are in the Appendix.

Each specification (column) in Table 3 represents a combination of a treated (CRP) sample and a control (non-CRP) sample. The results generate consistent estimates within each column, so the results are not driven by functional form. However, as expected, the results change greatly between columns.

Specifications I and II in Table 3 show results using the CRP-Eligible sample (CRP parcels that were part of early CRP signup waves) as the treatment group. Regardless of the control (non-CRP) group chosen, CRP-Eligible parcels are less likely to be farmed than are counterfactuals. Recall from Table 1 that $86.3 \%$ of CRP-Eligible land stayed in CRP. As argued in the Methods section, comparing CRP-Eligible parcels with non-CRP parcels does not address the question of post-CRP land use since much of the eligible land stayed in the program.

Specifications I and III in Table 3 show results using Control-All (non-CRP land that was farmed in 1982) as the control group. In both cases, again, CRP land is less likely to be farmed. This result is again informed by Table 1 . Most of Control-All is continuously farmed. When I compare CRP land to this land, I ask whether CRP makes a parcel more likely to be farmed as compared to most of the nation's farmland, including the best land. This is not causal; it is driven by unobservable differences in land quality $(z)$ and transition costs.

Specification IV in Table 3 is the most revealing. Here, the treatment group is CRP-Exit: land that exited the CRP between 1992 and 1997. It is compared to Control-Unfarmed: land that, though farmed in 1982, was in some other land use in the intervening years. Control-Unfarmed land has been revealed, by its chosen land use, to be like CRP land: marginal in quality $(\underline{z} \leq z \leq \bar{z})$ and facing transition costs to enter farming. Therefore, the Control-Unfarmed land is 
the best counterfactual for CRP-Exit land for this research question. My analysis shows that CRP-Exit land is more likely to be farmed than the non-CRP land. This treatment effect is statistically significant and consistent across functional forms. At $22-27 \%$, it is also economically significant.

To restate this result, the CRP seems to have made this land $22-27 \%$ more likely to be farmed than it would have been had it never been in the CRP. This result is expected if the returns to agriculture have increased on this land, which in turn is expected because CRP improves land quality, including unobservable quality $z$. (Control-Unfarmed land should have also improved while it was not farmed, although most likely not as much, as argued above.) Again, this is an estimate of a local effect just on the CRP land that exited the program. Nonetheless, it demonstrates the existence of temporal spillovers.

As discussed in the Methods section, these results may be biased toward zero if ControlUnfarmed land is unobservably better than CRP-Exit land or if there is a delay in transitioning into farming, and the results may be biased upward if Control-Unfarmed land is unobservably worse than CRP-Exit land or is in a long fallow cycle. This upward bias is less likely because Control-Unfarmed was shown to be (on average) better in observable qualities than CRP-Exit, and because the NRI tries to accurately record fallow land, but it is still possible.

These results are robust to a number of alternative specifications.

First, I noted above that selective exit CRP land limits the analysis, since I only address selective entrance. Selective exit means that I can only conclude that the CRP causes some land to be more likely to be farmed, and the magnitude of this effect may be diminished for CRP land that has not exited. If only the best CRP land exits, then CRP-Exit may contain the upper envelope of CRP land (say, $z_{\text {mid }} \leq z \leq \bar{z}$ for a $z_{\text {mid }}$ such that $\underline{z}<z_{\text {mid }}<\bar{z}$ ). Control-Unfarmed 
would then contain a wider range of land quality $(\underline{z} \leq z \leq \bar{z})$. Since observable land quality measures have a relationship with land use and thus perhaps with unobservable land quality $z$, I restrict the subsamples to only the observably best land for a set of four robustness checks. In two of these robustness checks, I restrict only the non-CRP land subsample to observably best land; in the other two, I thusly restrict both the CRP and non-CRP land subsamples. For both of these restricted subsamples, I define the best land according to the prime farmland indicator in one specification and according to the presence of a good (unrestricted) land classification in the other. Results are robust to these checks, with coefficients still significant and in nearly all specifications increased in magnitude, as shown in Table 4 alongside the original specification. Also, since Control-Unfarmed may overall be better than CRP-Exit land since the farmers chose not to enroll this land in the CRP, I run a specification in which the Control-Unfarmed group is restricted to only highly erodible land (land with erodibility index 8 or more). These results, also shown in Table 4, are also robust and are again stronger than the original specification. This implies that Control-Unfarmed land as a whole is higher-quality than CRP-Exit land as a whole. Again, if this were true, it would imply that my results understate the effect of CRP participation. The CRP-Exit / Control-Unfarmed result also persists nearly unchanged (now in the range 21-24\%) when Control-Unfarmed parcels are chosen only from counties where CRP enrollment might have been near the countywide enrollment cap (detailed results available on request). In these counties, Control-Unfarmed land is more likely to have made a bid for a CRP contract and been rejected, and thus this land could be better counterfactual land. ${ }^{12}$

\footnotetext{
${ }^{12}$ Another interesting robustness check would be to study counties that had particularly high CRP bid rejections in the early rounds, since this may imply that large amounts of the Control-Unfarmed land was rejected from CRP and thus may be particularly like the CRP land. Personal correspondence with USDA staff reveals that rejections those first waves would not be random, being largely caused by high bids.
} 
Finally, the use of Control-Unfarmed land in the intervening years can also tell us about that land's unobservable quality $z$. When that subsample is restricted to only parcels that were farmed in 1987, which may have a higher $z$, the CRP land still appears more likely to be farmed although the magnitude is slightly reduced to $17-21 \%$ (detailed results available on request).

\section{Multinomial Land Use Outcome Results}

Cultivated cropping is the land use of greatest interest. However, it is also interesting to learn how CRP participation affects the entire distribution of final land uses. Table 5 presents multinomial logit analyses of the land use outcome. The specifications (columns) again correspond to pairs of treatment and control groups. Land use categories are: cultivated cropland, non-cultivated cropland, pasture, CRP, and other. ${ }^{13}$ When CRP-Eligible is compared to either control group (Specifications I and II in Table 5), the results are mainly driven by the tendency of this CRP land, while probably eligible to exit, to stay in the program. CRP-Eligible land is much more likely to be in CRP in 1997, and less likely to be cultivated, than the control group. Also, when compared to the Control-Unfarmed group, CRP-Eligible land is less likely to become non-cultivated cropland or pasture, which again is because most of CRP-Eligible stayed in the CRP (and much of Control-Unfarmed became or remained non-cultivated cropland or pasture). In Specifications III and IV of Table 5, in which CRP-Exit land is compared to non-CRP land, the results again depend on the set of control land used. When CRP-Exit is compared to Control-All (Specification III), the ex-CRP land is less likely to be farmed and has a greater tendency to go into pasture, non-cultivated cropland (hay), and other uses. This is intuitive: most land that exits CRP is planted with grasses and legumes as a conservation cover. The conversion

\footnotetext{
13 "Other" includes rangeland, forest, and "other rural"; these uses make up small but significant elements of CRPEligible (2.19\%), CRP-Exit (14.63\%), Control-All (2.22\%), and Control-Unfarmed (17.55\%).
} 
to pasture is trivial while the conversion to hay or other non-cultivated uses may also be inexpensive. When CRP-Exit is compared to Control-Unfarmed in Specification IV, the ex-CRP land is $26 \%$ more likely to become cultivated cropland, in the range of the binary model estimates. The CRP-Exit land is less likely than Control-Unfarmed parcels to be non-cultivated cropland or pasture in 1997 . This is probably because over $80 \%$ of Control-Unfarmed land had already been in non-cultivated cropland (47.54\%) or pasture $(36.25 \%)$ in 1992 .

I previously noted that, although transition costs should be held constant, CRP land has less opportunity to transition than Control-Unfarmed land because CRP contracts end in 1996. This could result in a differential under-measurement of transition. The multinomial analysis supports this possibility. Much of CRP-Exit that does not go into farming ends up as noncultivated cropland or pasture, but both pasture and non-cultivated cropland tend to convert to cultivated cropland: $44.8 \%$ of 1992 non-cultivated cropland and $28.2 \%$ of 1992 pasture was farmed in 1997. ${ }^{14}$ This differential under-measurement would bias CRP's tendency to enter cultivated cropland toward zero, implying that my estimated effect of CRP participation is again understated.

\section{Conservation Practice Results}

The 1997 NRI sample contains data on whether any of 22 different conservation practices was adopted on cultivated cropland, summarized in Table 1 for the populations of interest. Of all acreage cultivated in $1997,22.77 \%$ was engaged in some conservation practice, generally intended to conserve water or reduce erosion. The most popular practices were terraces $(6.2 \%$ of land), contour farming (5.76\%), grassed waterways (4.28\%), and surface drainage $(4.02 \%)$. In

\footnotetext{
${ }^{14}$ High rates of conversion to cropping over five-year periods may imply error in NRI's verification of fallow cycles.
} 
some cases, these practices are strongly recommended or required for land that is very sensitive (e.g., highly erodible). Government programs at various levels promote and subsidize practices of this type.

Is ex-CRP land that becomes cultivated cropland more likely than other land to adopt these conservation practices? Table 1 shows that unconditionally, cultivated ex-CRP land appears more likely to adopt conservation practices than either cultivated Control-All or cultivated Control-Unfarmed land. However, this unconditional result is confounded by differences in land quality and other factors.

The conservation practice analysis can be performed in much the same way that the land use outcome analysis was performed. However, since some low-quality land is required to adopt conservation practices and these requirements are not evident in the data, the sample must first be restricted to include only land that is not highly erodible, with an erodibility index of 8 or less (results without the erodibility index restriction are similar, and available on request).

Even after this extra restriction on the samples, causality cannot be attributed to the CRP. While significant results could point to a causal role for the CRP, there are competing explanations. It could be that landowners concerned with stewardship (high- $\sigma$ farmers) are drawn to both CRP and the use of conservation practices if they farm. It could also be that landowners who are more familiar with government programs are more likely to enter CRP and to take up a conservation practice promoted by local farm office officials.

Table 6 shows the coefficient of (or marginal effect for) CRP participation on the adoption of some conservation practice in 1997. The columns again represent different combinations of ex-CRP and control (non-CRP) land, with data restricted to non-highly-erodible land that was cultivated in 1997. In Specification I, the control group includes the portion of 
Control-All (all land farmed in 1982) that was farmed in 1997. For this comparison, the CRP land is neither more nor less likely to adopt a conservation practice. (Most of Control-All was farmed in 1992, but data on conservation practices for 1992 are not available.)

For Specification II of Table 6, the control group includes the portion of ControlUnfarmed (land farmed in 1982 but not 1992) that was farmed in 1997. In this specification, both CRP and non-CRP parcels faced a transition back into farming. Adopting a new conservation practice requires investment of time and money, so transition costs into farming with conservation practices are greater than transition costs into farming without conservation practices. CRP parcels are roughly $4 \%$ more likely to adopt a conservation practice than this very similar land. This is large relative to the baseline adoption rate of conservation practices of $18.1 \%$ for this land.

\section{Conclusion}

Temporal spillovers can offset some benefits of payments for environmental services programs if participation causes intensification of later activity. The Conservation Reserve Program may be prone to such effects because it uses temporary voluntary contracts to conserve agricultural land, but while in the program, the land improves in quality and thus becomes more productive to farm. I find that CRP participation causes at least some land to be $22-27 \%$ more likely to be farmed than it would have been had it never been in the program. This result is "local" in the sense that the estimate only applies directly to land that voluntarily exited the program at the time of interest, but it demonstrates the temporal spillover effect as an item of concern in land conservation. This result is congruent with other research findings that the CRP improves land quality, because that improvement should increase the returns to cropping. The CRP may act as a 
long, subsidized fallow period for some landowners. Other payment for environmental services programs may be susceptible to this issue as well.

An innovation of my analysis is the use of a sample re-specification step. I use observed land use to infer the range of an unobservable land quality factor I call $z$, since marginal land is the land most likely to be taken out of cultivation either for conservation or for other uses. This process essentially "matches" samples of conserved and non-conserved land that should have similar values of $z$. If such a step is not done, different ranges of unobservable land quality $z$ can cause results biased to falsely imply persistent benefits of conservation because low-quality land enters conservation.

What are the broader implications of these results? Temporal spillovers are real and demonstrable. Spatial spillovers (slippage) have already been an element of concern because of their ability to reduce benefits of payment for environmental services programs. We must also be concerned with the temporal effects of these programs. These effects may be more insidious because they are hard to detect. Temporal spillovers may also be fundamentally more damaging because they do not simply shift activity but actually increase intensive use because the characteristics of the land being conserved changes while in the program.

Acknowledging the presence of temporal spillovers may require us to change elements of policy design. Conservation payments may currently be higher than necessary, since land quality improvements provide private benefits to landowners when the later intensive use is undertaken. This might not be the case, of course, if lowered conservation participation bids reflect these benefits. Additionally, it may be possible to design conservation contracts in ways that would reduce these spillovers. For example, longer contracts might provide more in-contract environmental improvements relative to the out-of-contract reduction in environmental benefits. 
However, if such changes were made, programs could see reduced program participation or requests for higher payments.

Finally, temporal spillovers may have an interesting interaction with spatial spillovers. Imagine that as Parcel A enters into a temporary conservation contract, marginal Parcel B is pushed by spatial slippage to enter intensive use. When Parcel A then exits the contract, this increases the supply of land available for intensive uses and pushes down prices. That may push some land that had previously been in intensive use into nonuse. Parcel B may then "reverse slip" out of its intensive use. Of course, if Parcel A was actually improved while in the program, these effects should not net out since Parcel A will be more productive than it was before it enrolled. 


\section{Appendix}

In this appendix, I demonstrate that matching analysis provides point estimates that are similar to the point estimates provided by the other estimation methods I use in the analysis of land use outcome and of conservation practice take-up.

Regression analysis does not account for the fact that if land in the control (non-CRP) group is very unlike land in the treatment (CRP) group, regression results could be biased, as demonstrated in Rosenbaum (2002). This is because treatment units are compared to inappropriate control units. Given the inevitable mis-specification of a model, differences in sample characteristics may drive apparent differences in outcomes. Matching analysis can counteract this bias. The matching algorithm chooses the control (non-CRP) units that are "most like" the treated (CRP) units based on observable characteristics.

It must be noted, however, that standard errors cannot be correctly calculated for the average treatment effects estimated through matching. As noted in the description of the data, the NRI is a stratified sample. Within the NRI, weights (denoted "xfact" in the data) represent how much acreage each data point represents. While use of these weights is handled in standard ways in regression and other analysis, there is a difficulty with regard to matching. As noted in the documentation of the Stata package psmatch2, “As far as we know it's not really clear in the literature how to accommodate sample weights in the context of matching" (Leuven and Sianesi, 2003).

Thus, matching point estimates are provided in this Appendix for comparison, although the standard errors reported are not accurately estimated. 
I perform all matching analyses using the Stata package psmatch2 (Leuven and Sianesi, 2003). "Treated" (i.e., CRP) parcels are matched to "control" (non-CRP) parcels using one-toone nearest neighbor matching with replacement and without calipers. A common support is imposed. A propensity score is estimated to determine a given parcel's likelihood of being in CRP. The propensity score estimation uses a logit regression of land quality variables (prime and good land capability classification indicators), the 1996 rent and rent change variables, county level demographics (population density, median income, poverty rate, and measures of race and age distribution) plus dummies for which of 10 USDA-defined geographical regions the parcel lies in. The matching uses a Mahalanobis metric, which is a way of calculating distances in multidimensional space. The Mahalanobis metric is calculated from the all of the variables listed as elements of the propensity score, with the propensity score included as well. (The matching is performed on the odds ratio of the propensity score.) The matching algorithm compares CRP and non-CRP parcels with characteristics that are similar, as determined by this metric. I calculate the average treatment effect on the treated (ATT) based on the matched sample.

First, I replicate the naïve analysis undertaken in Table 2, ignoring selective entry into CRP. Here, I use all NRI observations for which county-level rent data are available and do not split the data up into subsamples before performing matching analysis. Using the matched sample, the estimate of average treatment effect on the treated indicates that CRP land is $74.8 \%$ (standard error 0.014) less likely to be farmed than all other land.

For the core elements of the analysis, matching results are compared to results from regression analyses in the tables accompanying this Appendix. (Covariate balancing tables for matching analyses are available upon request.) Table A-1 replicates the land use outcome results in Table 3, showing that when matching is used, the point estimates of the effect of CRP 
participation are very close to the values estimated through the other methods. Table A-2 replicates the land use outcome robustness checks in Table 4, and again the matching estimates are quite close to the regression estimates. Table A-3 examines conservation practice results as in Table 6. The result comparing farmed CRP-Exit parcels to farmed Control-All parcels shows an estimated effect of zero, which is slightly but not significantly smaller than the effect estimated in regressions. The result comparing farmed CRP-Exit parcels to farmed Control-Unfarmed parcels shows an effect slightly but not significantly larger than the effect estimated in the regressions.

Thus, while the standard errors are not reliable, the point estimates derived from the matching analysis confirm the results demonstrated in regressions. Why do matching results differ so little from the results of regression analysis, and why do differences between the specifications persist even when matching is used? Matching can only be performed on the basis of observable characteristics. Matching simply removes the bias that can occur if the control group is very different from the treatment group in observable ways. It cannot control for differences in unobservable characteristics. I argue that differences in unobservables are very important in this setting: unobservable land quality $z$ drives both entry into the CRP and tendency to farm in the end period. Matching cannot control for these differences. In fact, my sample specification step performs a function like matching at a data subsample level: I infer ranges of $z$ based on land use, and my choice of subsamples to compare is a choice to match based on range of $z$.

I check the robustness of the main matching results using Rosenbaum's recommended sensitivity test (Rosenbaum, 2002). This test simulates conditions in which the treatment variable (1992 CRP participation) and the outcome (1997 farming of the land) are both driven by an 
unobservable factor. This test assumes that the unobservable factor determines with certainty whether land will be farmed in 1997 . The correlation between this unobservable factor and the propensity to receive treatment (here, likelihood of being in CRP) is varied, and the test reports the range of unobservable values for which the matching result is still valid. When CRP-Exit land is compared to Control-All and Control-Unfarmed land, the result is robust up to an unobservable factor of 3.6 and 2.7 respectively. That is, even if some parcels are 3.6 (or 2.7) times as likely to enter CRP due to an unobservable factor perfectly correlated with later farming, the matching result showing that CRP-Exit land is more likely to be farmed than Control-Unfarmed (and less likely to be farmed than Control-All) would still indicate a positive causal effect. ${ }^{15}$ These results do not tell us that there is such a factor; it simply indicates how strong a factor would have to be to create these results under the very conservative assumption that this unobservable factor wholly determines farming outcome.

I perform another Rosenbaum test for sensitivity to unobservable factors on the conservation practice result, and the conservation practice result is very sensitive to unobservable factors that increase the CRP signup rate by as little as $40 \%$. This reinforces the possibility that these results may be driven by unobservable selection.

\footnotetext{
${ }^{15}$ When CRP-Eligible land is compared to Control-All the result is robust up to an unobservable factor of at least 6; when CRP-Eligible is compared to Control-Unfarmed the result is robust up to a factor of 2.5.
} 


\section{References}

Chouinard, Hayley H., Paterson, Tobias, Wandschneider, Philip R. and Ohler, Adrienne M., 2008. "Will Farmers Trade Profits for Stewardship? Heterogeneous Motivations for Farm Practice Selection." Land Economics, 84(1), 66-82.

Cooper, Joseph C. and Osborn, Tim C., 1998. "The Effect of Rental Rates on the Extension of Conservation Reserve Program Contracts." American Journal of Agricultural Economics, 80(1), 184-194.

De La Torre Ugarte, Daniel and Hellwinckel, Chad, 2006. "Analysis of the Economic Impacts on the Agricultural Sector of the Elimination of the Conservation Reserve Program." University of Tennessee Agricultural Policy Analysis Center Report, Knoxville, TN, USA.

De La Torre Ugarte, Daniel, Ray, Daryll E., White, Richard L. and Dicks, Michael R., 1995. "The Conservation Reserve Program." The 1995 Farm Bill: A Special Series of Alternative Policy Analyses. Agricultural Policy Analysis Center, The University of Tennessee, and Great Plains Agricultural Policy Center, Oklahoma State University, Knoxville, TN and Stillwater, OK.

Feather, Peter, Hellerstein, Daniel and Hansen, Leroy, 1999. "Economic Valuation of Environmental Benefits and the Targeting of Conservation Programs: The Case of the CRP." United States Department of Agriculture Economic Research Service Report \#778, Washington, DC, USA.

Johnson, Philip N., Misra, Sukant K. and Ervin, Terry R., 1997. "A Qualitative Choice Analysis of Factors Influencing Post-CRP Land Use Decisions." Journal of Agricultural and Applied Economics, 29(1), 163-173.

Leuven, Edwin and Sianesi, Barbara, 2003, "PSMATCH2: Stata module to perform full Mahalanobis and propensity score matching, common support graphing, and covariate imbalance testing." http://ideas.repec.org/c/boc/bocode/s432001.html This version version 4.0.6 17may2012.

Lubowski, Ruben N., Plantinga, Andrew J. and Stavins, Robert N., 2008. "What Drives LandUse Change in the United States? A National Analysis of Landowner Decisions." Land Economics, 84(4), 529-550.

Roberts, Michael J. and Lubowski, Ruben N., 2007. "Enduring Impacts of Land Retirement Policies: Evidence from the Conservation Reserve Program." Land Economics, 83(4), 516-538. 
Rosenbaum, Paul R., 2002, Observational Studies. Springer-Verlag, New York.

Sheeder, Robert J. and Lynne, Gary D., 2011. "Empathy-Conditioned Conservation: "Walking in the Shoes of Others" as a Conservation Farmer." Land Economics, 87(3), 433-452.

Shoemaker, Robbin, 1989. "Agricultural Land Values and Rents under the Conservation Reserve Program." Land Economics, 65(2), 131-137.

Uri, Noel D., 2001. "A Note on Soil Erosion and Its Environmental Consequences in the United States." Water, Air \& Soil Pollution, 129(1-4), 181-197.

US Department of Agriculture, 2001. "1997 National Resources Inventory (revised December 2000)." National Resources Conservation Service, Washington, DC, and Statistical Laboratory, Iowa State University, Ames, IA.

US Department of Agriculture, Natural Resources Conservation Service, 2009. "National Soil Survey Handbook, title 430-VI." Available online at: soils.usda.gov/technical/handbook, accessed October 12009.

Wallace, Barbara and Clearfield, Frank, 1997. "Stewardship, Spirituality, and Natural Resources Conservation: A Short History." USDA-NRCS Social Sciences Institute Technical Report Release 2.2, Washington, DC.

Wu, Junjie, 2000. "Slippage Effects of the Conservation Reserve Program." American Journal of Agricultural Economics, 82(4), 979-992.

Young, C. Edwin, Skully, David W., Westcott, Paul C. and Hoffman, Linwood, 2005.

"Economic Analysis of Base Acre and Payment Yield Designations Under the 2002 U.S. Farm Act." United States Department of Agriculture Economic Research Report 12, Washington, DC, USA. 
Figures and Tables

Figure 1. Unobservable land quality

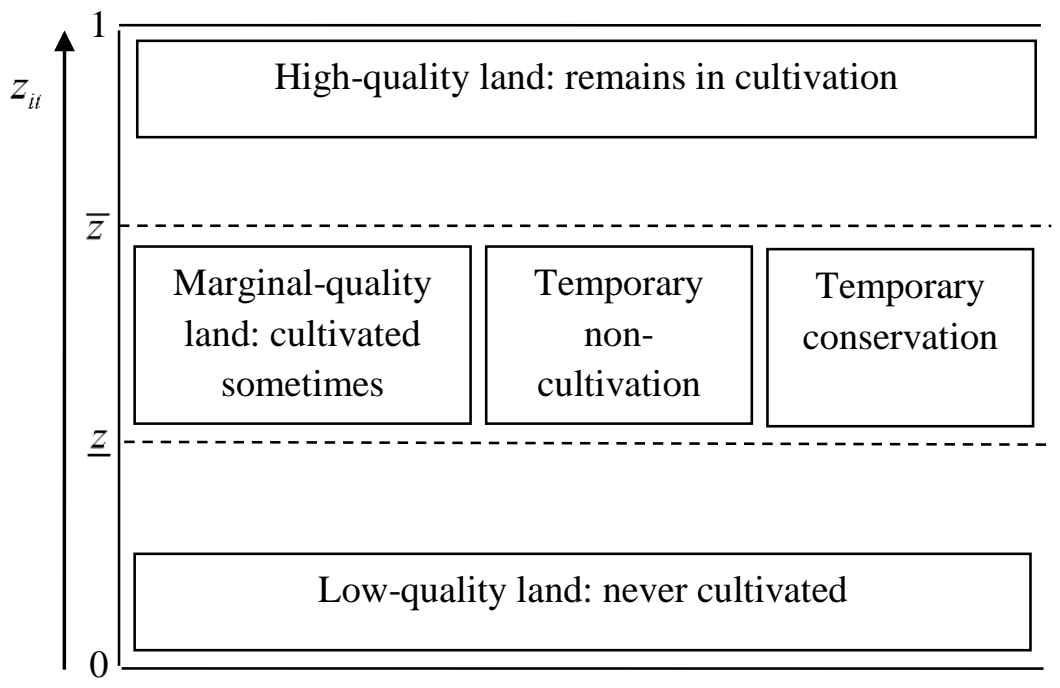


Figure 2: NRI and CRP timeline with land uses of specified subsamples

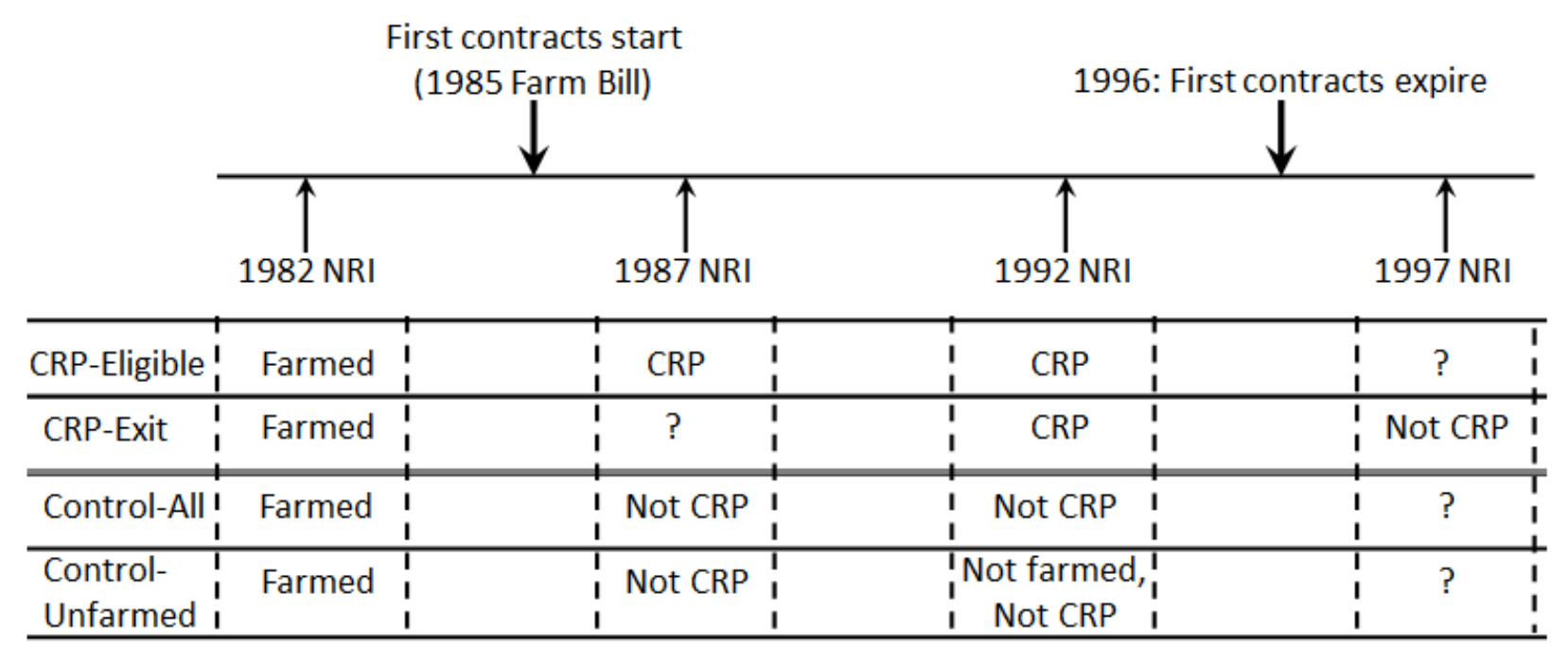


Table 1. Characteristics of Land in Subpopulations of Interest

\begin{tabular}{|c|c|c|c|c|c|c|}
\hline & $\begin{array}{c}\text { Farmed in } \\
1982\end{array}$ & $\begin{array}{l}\text { CRP in } \\
1992\end{array}$ & CRP-Exit & $\begin{array}{l}\text { CRP- } \\
\text { Eligible }\end{array}$ & $\begin{array}{l}\text { Control- } \\
\text { All }\end{array}$ & $\begin{array}{l}\text { Control- } \\
\text { Unfarmed }\end{array}$ \\
\hline \multirow[t]{2}{*}{ Prime farmland? ${ }^{a, d}$} & 0.566 & 0.286 & 0.345 & 0.262 & 0.576 & 0.438 \\
\hline & (0.002) & (0.002) & (0.009) & (0.004) & (0.002) & $(0.006)$ \\
\hline \multirow{2}{*}{ Good land class? ${ }^{\mathrm{a}, \mathrm{c}, \mathrm{d}}$} & 0.952 & 0.875 & 0.888 & 0.873 & 0.960 & 0.895 \\
\hline & $(0.001)$ & $(0.002)$ & $(0.005)$ & $(0.002)$ & $(0.001)$ & $(0.004)$ \\
\hline \multirow[t]{2}{*}{ Erodibility index ${ }^{\mathrm{a}, \mathrm{d}}$} & 7.330 & 12.990 & 12.209 & 13.759 & 7.176 & 10.579 \\
\hline & $(0.026)$ & $(0.971)$ & $(0.221)$ & $(0.108)$ & $(0.030)$ & $(0.221)$ \\
\hline \multirow{2}{*}{ Slope ${ }^{a, d}$} & 2.759 & 4.260 & 4.841 & 4.270 & 2.783 & 4.166 \\
\hline & $(0.009)$ & $(0.018)$ & $(0.010)$ & $(0.025)$ & $(0.011)$ & $(0.046)$ \\
\hline \multirow[t]{2}{*}{ Return: crops ${ }^{b}$} & 93.365 & 80.739 & 96.169 & 81.074 & 94.863 & 98.626 \\
\hline & $(0.150)$ & (0.097) & (0.754) & $(0.275)$ & $(0.168)$ & $(0.820)$ \\
\hline \multirow{2}{*}{$\begin{array}{l}\text { Return: government } \\
\text { payments }{ }^{b}\end{array}$} & 10.967 & 8.856 & 9.364 & 8.870 & 11.192 & 9.023 \\
\hline & (0.014) & (0.010) & (0.063) & $(0.275)$ & $(0.016)$ & $(0.061)$ \\
\hline \multirow[t]{2}{*}{ Return: pasture ${ }^{\mathrm{b}}$} & 29.050 & 27.052 & 30.967 & 28.109 & 29.267 & 31.005 \\
\hline & (0.064) & (0.024) & $(0.181)$ & (0.104) & $(0.072)$ & $(0.308)$ \\
\hline \multirow[t]{2}{*}{ Return: range ${ }^{\mathrm{b}}$} & 10.912 & 11.228 & 8.937 & 11.179 & 10.872 & 10.553 \\
\hline & (0.032) & $(0.027)$ & $(0.201)$ & (0.064) & (0.036) & $(0.145)$ \\
\hline \multirow[t]{2}{*}{ Return: forest ${ }^{b}$} & 11.725 & 12.189 & 21.662 & 12.807 & 11.659 & 14.453 \\
\hline & (0.044) & (0.011) & $(0.140)$ & $(0.065)$ & (0.049) & $(0.181)$ \\
\hline \multirow[t]{2}{*}{ Return: urban $^{\mathrm{b}}$} & 2331.954 & 2426.994 & 2450.342 & 2566.866 & 2318.095 & 2260.462 \\
\hline & $(4.968)$ & $(3.711)$ & $(31.431)$ & (8.409) & $(5.517)$ & (21.918) \\
\hline \multirow{2}{*}{$\begin{array}{l}\text { Early CRP signup } \\
\text { wave }\end{array}$} & - & 0.617 & 0.821 & 1 & - & - \\
\hline & & (0.002) & $(0.005)$ & (0) & & \\
\hline \multirow{4}{*}{$\begin{array}{l}\text { CRP cover of grass in } \\
1992 \\
\text { CRP in } 1992\end{array}$} & - & 0.906 & 0.920 & 0.927 & - & - \\
\hline & & $(0.001)$ & $(0.004)$ & $(0.001)$ & & \\
\hline & 0.082 & 1 & 1 & 1 & - & - \\
\hline & $(0.000)$ & (0) & (0) & (0) & & \\
\hline \multirow[t]{2}{*}{ CRP in 1997} & 0.078 & 0.895 & - & 0.863 & 0.007 & 0.005 \\
\hline & $(0.000)$ & $(0.001)$ & & $(0.002)$ & $(0.000)$ & $(0.000)$ \\
\hline \multirow[t]{2}{*}{ Farmed in 1992} & 0.821 & - & - & - & 0.921 & - \\
\hline & (0.001) & & & & $(0.001)$ & \\
\hline \multirow[t]{2}{*}{ Farmed in 1997} & 0.790 & 0.053 & 0.528 & 0.068 & 0.891 & 0.271 \\
\hline & $(0.001)$ & $(0.001)$ & (0.007) & (0.002) & $(0.001)$ & $(0.005)$ \\
\hline \multirow{2}{*}{$\begin{array}{l}\text { Conservation practice } \\
\text { if farmed in } 1997\end{array}$} & 0.233 & 0.251 & 0.258 & 0.271 & 0.232 & 0.181 \\
\hline & $(0.001)$ & $(0.013)$ & $(0.014)$ & $(0.016)$ & $(0.002)$ & $(0.009)$ \\
\hline \multirow{4}{*}{$\begin{array}{l}\text { population density } \\
\text { (1996) } \\
\text { City 100K or bigger } \\
\text { present (1996)? }\end{array}$} & 76.066 & 29.152 & 40.340 & 25.930 & 52.931 & 64,681 \\
\hline & $(0.421)$ & $(0.218)$ & (1.536) & $(0.353)$ & $(0.263)$ & $(1.033)$ \\
\hline & 0.191 & 0.076 & 0.096 & 0.069 & 0.147 & 0.186 \\
\hline & $(.001)$ & $(0.001)$ & (0.006) & $(0.001)$ & (0.001) & $(0.004)$ \\
\hline \multirow{8}{*}{$\begin{array}{l}\text { City } 500 \mathrm{~K} \text { or bigger } \\
\text { present (1996)? } \\
\text { percent of population } \\
\text { in urban areas (2000) } \\
\text { median household } \\
\text { income (1997) } \\
\text { poverty rate (1997) }\end{array}$} & 0.084 & 0.017 & 0.023 & 0.015 & 0.050 & 0.081 \\
\hline & $(0.001)$ & $(0.000)$ & (0.003) & $(0.001)$ & $(0.001)$ & $(0.002)$ \\
\hline & 0.405 & 0.318 & 0.346 & 0.321 & 0.381 & 0.355 \\
\hline & $(0.001)$ & (0.001) & $(0.005)$ & (0.001) & $(0.001)$ & $(0.003)$ \\
\hline & $32,781.38$ & $30,843.39$ & $32,009.19$ & $30,919.78$ & $32,564.94$ & $31,898.04$ \\
\hline & $(16.403)$ & (9.589) & $(87.655)$ & $(24.523)$ & $(19.520)$ & $(96.725)$ \\
\hline & 14.255 & 15.297 & 13.886 & 15.297 & 13.932 & 14.806 \\
\hline & $(0.017)$ & (0.010) & (0.073) & (0.023) & $(0.021)$ & $(0.078)$ \\
\hline \multirow{4}{*}{$\begin{array}{l}\text { unemployment rate } \\
\text { (1996) } \\
\text { percent black (1996) }\end{array}$} & 5.213 & 5.055 & 5.212 & 5.023 & 4.956 & 5.537 \\
\hline & $(0.010)$ & $(0.005)$ & $(0.046)$ & $(0.015)$ & $(0.010)$ & $(0.034)$ \\
\hline & 0.063 & 0.046 & 0.043 & 0.041 & 0.051 & 0.086 \\
\hline & $(0.000)$ & $(0.000)$ & $(0.002)$ & $(0.000)$ & $(0.000)$ & $(0.002)$ \\
\hline percent white (1996) & 0.911 & 0.923 & 0.936 & 0.932 & 0.923 & 0.889 \\
\hline & $(0.000)$ & $(0.000)$ & $(0.002)$ & $(0.001)$ & $(0.000)$ & $(0.002)$ \\
\hline
\end{tabular}




\begin{tabular}{lcccccc} 
median age (1996) & 35.837 & 36.322 & 36.139 & 36.287 & 36.051 & 35.520 \\
& $(0.011)$ & $(0.006)$ & $(0.059)$ & $(0.016)$ & $(0.013)$ & $(0.048)$ \\
percent under 18 & 0.272 & 0.275 & 0.272 & 0.277 & 0.271 & 0.271 \\
$(1996)$ & $(0.000)$ & $(0.000)$ & $(0.000)$ & $(0.000)$ & $(0.000)$ & $(0.000)$ \\
percent over 65 & 0.156 & 0.164 & 0.160 & 0.163 & 0.161 & 0.151 \\
$(1996)$ & $(0.000)$ & $(0.000)$ & $(0.001)$ & $(0.000)$ & $(0.000)$ & $(0.001)$ \\
\hline Observations & 232,953 & 19,782 & 2,400 & 10,669 & 154,512 & 14,972 \\
Average acres per & 16.678 & 17.208 & 13.090 & 17.641 & 17.472 & 14.115 \\
sample point & $(0.028)$ & $(0.087)$ & $(0.169)$ & $(0.120)$ & $(0.030)$ & $(0.099)$ \\
Hundreds of acres & $3,754,446$ & 340,400 & 31,417 & 188,208 & $2,699,633$ & 211,329 \\
\hline
\end{tabular}

Standard errors in parentheses

a 1997 land characteristic data

b 1996 land use returns

c "Good land class" is an indicator for land classification of 1, 2, 3, or 4, indicating few restrictions on use

${ }^{\mathrm{d}}$ Land characteristic data only available for certain land uses, so these are means over available data: erodibility not available for pasture; erodibility and slope not available for pasture, range, forest, other rural; erodibility, slope, prime, and land class not available for urban, water, and federal land. Since the rightmost four columns are used in later analysis, this Table's summaries in these columns include only observations with non-missing 1997 land class. 
Table 2. Land Use Results with Naïve (Un-Pre-Processed) Sample

\begin{tabular}{lccc}
\hline & Specification I & Specification II & Specification III \\
\hline CRP dummy & $-0.236^{* * *}$ & & \\
Early CRP dummy & $(0.005)$ & $-0.219^{* * * *}$ & \\
& & $(0.006)$ & \\
Late CRP dummy & $-0.262^{* * *}$ & \\
& & $(0.005)$ & $0.237^{* * *}$ \\
CRPEXIT dummy & & $(0.008)$ \\
& & & $-0.291^{* * *}$ \\
CRPNOEXIT dummy & & & $(0.005)$ \\
& & & $0.626^{* * *}$ \\
FARM92 dummy & $0.627 * * *$ & $0.627 * * *$ & $(0.005)$ \\
& $(0.005)$ & $(0.005)$ & 172,048 \\
\hline (observations) & 172,048 & 172,048 & $3,006,841$ \\
$N$ (hundreds of acres) & $3,006,841$ & $3,006,841$ & $41,809.71$ \\
$F$ & $13,573.93$ & $17,026.94$ & 0.633 \\
$R^{2}$ & 0.616 & 0.617 & \\
\hline
\end{tabular}

* significant at $10 \%, * *$ significant at $5 \%$; *** significant at $1 \%$

Standard errors in parentheses. Regressions are OLS. All included land was cultivated in 1982, is in a county for which rent data is available, and does not enter 1997 land uses: urban/built-up, water, or federal. Specifications control for 1997 land characteristics (prime farmland indicator, good land class indicator), 1996 land use rents and changes, 1996 demographics (population density, median household income, poverty rate, unemployment rate, percent black, percent white, median age, percent under 18, percent over 65), region code dummies, and land characteristic $\mathrm{x}$ rent interactions. Survey regressions performed with data points appropriately weighted and clustered errors. 
Table 3. Land Use Results with Pre-Processed Samples

\begin{tabular}{lcccc}
\hline Specification: & I & II & III & IV \\
\hline What CRP land & Early signup & Early signup & Exit 1992-7 & Exit 1992-7 \\
included? & (CRP-Eligible) & (CRP-Eligible) & (CRP-Exit) & (CRP-Exit) \\
What non-CRP & All land & Not farmed & All land & Not farmed \\
(previously farmed) & (Control-All) & 1992 (Control- & (Control-All) & 1992 (Control- \\
land included? & & Unfarmed) & & Unfarmed) \\
\hline OLS & $-0.777^{* * *}$ & $-0.191^{* * *}$ & $-0.316^{* * *}$ & $0.224^{* * * *}$ \\
& $(0.003)$ & $(0.006)$ & $(0.007)$ & $(0.009)$ \\
Logit (marginal effect) & $-0.838^{* * *}$ & $-0.224^{* * *}$ & $-0.286^{* * *}$ & $0.268^{* * *}$ \\
& $(0.003)$ & $(0.007)$ & $(0.007)$ & $(0.012)$ \\
Probit (marginal effect) & $-0.827^{* * *}$ & $-0.229^{* * *}$ & $-0.303 * * *$ & $0.259^{* * *}$ \\
& $(0.002)$ & $(0.007)$ & $(0.007)$ & $(0.011)$ \\
\hline$n$ (observations) & 165,188 & 25,652 & 156,919 & 17,383 \\
$N$ (hundreds of acres) & $2,887,997$ & 399,719 & $2,731,206$ & 242,928 \\
\hline
\end{tabular}

* significant at $10 \%, * *$ significant at $5 \%$; *** significant at $1 \%$

All included land was cultivated in 1982, is in a county for which rent data is available, and does not enter 1997 land uses: urban/built-up, water, or federal. Specifications control for 1997 land characteristics (prime farmland indicator, good land class indicator), 1996 land use rents and changes, 1996 demographics (population density, median household income, poverty rate, unemployment rate, percent black, percent white, median age, percent under 18, percent over 65), region code dummies, and land characteristic x rent interactions. Survey regressions performed with data points appropriately weighted and clustered errors. 
Table 4. Land Use Robustness Checks for CRP-EXIT comparison to Control-Unfarmed

\begin{tabular}{|c|c|c|c|c|c|c|}
\hline Specification: & IV & IV-both-G & IV-both-P & IV-Ctrl-G & IV-Ctrl-P & IV-Ctrl-HEL \\
\hline $\begin{array}{l}\text { What CRP land } \\
\text { included? }\end{array}$ & $\begin{array}{l}\text { Exit 1992-7 } \\
\text { (CRP-Exit) }\end{array}$ & $\begin{array}{l}\text { Exit 1992-7 } \\
\text { (CRP-Exit)- } \\
\text { good land class }\end{array}$ & $\begin{array}{c}\text { Early signup } \\
\text { (CRP-Eligible) } \\
\text { - prime }\end{array}$ & $\begin{array}{l}\text { Exit 1992-7 } \\
\text { (CRP-Exit) }\end{array}$ & $\begin{array}{c}\text { Early signup } \\
\text { (CRP-Eligible) }\end{array}$ & $\begin{array}{l}\text { Exit 1992-7 } \\
\text { (CRP-Exit) }\end{array}$ \\
\hline $\begin{array}{l}\text { What non-CRP } \\
\text { (previously farmed) } \\
\text { land included? }\end{array}$ & $\begin{array}{l}\text { Not farmed } \\
1992 \text { (Control- } \\
\text { Unfarmed) }\end{array}$ & $\begin{array}{l}\text { Not farmed } 1992 \\
\text { (Control- } \\
\text { Unfarmed) - } \\
\text { good land class }\end{array}$ & $\begin{array}{c}\text { Not farmed } \\
1992 \text { (Control- } \\
\text { Unfarmed) - } \\
\text { prime }\end{array}$ & $\begin{array}{c}\text { Not farmed } 1992 \\
\text { (Control- } \\
\text { Unfarmed)- } \\
\text { good land class }\end{array}$ & $\begin{array}{c}\text { Not farmed } \\
1992 \text { (Control- } \\
\text { Unfarmed) - } \\
\text { prime }\end{array}$ & $\begin{array}{c}\text { Not farmed } \\
1992 \text { (Control- } \\
\text { Unfarmed) - } \\
\text { highly erodible }\end{array}$ \\
\hline OLS & $\begin{array}{c}0.224 * * * \\
(0.009)\end{array}$ & $\begin{array}{c}0.242 * * * \\
(0.010)\end{array}$ & $\begin{array}{c}0.274 * * * \\
(0.016)\end{array}$ & $\begin{array}{c}0.235 * * * \\
(0.010)\end{array}$ & $\begin{array}{c}0.257 * * * \\
(0.015)\end{array}$ & $\begin{array}{c}0.324 * * * \\
(0.010)\end{array}$ \\
\hline $\begin{array}{l}\text { Logit (marginal } \\
\text { effect) }\end{array}$ & $\begin{array}{c}0.268 * * * \\
(0.012)\end{array}$ & $\begin{array}{c}0.285 * * * \\
(0.013)\end{array}$ & $\begin{array}{c}0.333 * * * \\
(0.018)\end{array}$ & $\begin{array}{c}0.275^{* * *} \\
(0.013)\end{array}$ & $\begin{array}{c}0.312 * * * \\
(0.018)\end{array}$ & $\begin{array}{c}0.368 * * * \\
(0.013)\end{array}$ \\
\hline $\begin{array}{l}\text { Probit (marginal } \\
\text { effect) }\end{array}$ & $\begin{array}{c}0.259 * * * \\
(0.011)\end{array}$ & $\begin{array}{c}0.276 * * * \\
(0.012)\end{array}$ & $\begin{array}{c}0.318^{* * *} * \\
(0.018)\end{array}$ & $\begin{array}{c}0.267 * * * \\
(0.012)\end{array}$ & $\begin{array}{c}0.299 * * * \\
(0.017)\end{array}$ & $\begin{array}{c}0.365 * * * \\
(0.012)\end{array}$ \\
\hline $\begin{array}{l}n \text { (data points) } \\
N \text { (hundreds of acres) }\end{array}$ & $\begin{array}{c}17,383 \\
242,928\end{array}$ & $\begin{array}{c}15,625 \\
217,165\end{array}$ & $\begin{array}{c}7,796 \\
103,535\end{array}$ & $\begin{array}{c}15,862 \\
220,690\end{array}$ & $\begin{array}{c}9,326 \\
124,105\end{array}$ & $\begin{array}{c}13,300 \\
175,138\end{array}$ \\
\hline
\end{tabular}

$*$ significant at $10 \%, * *$ significant at $5 \%$; *** significant at $1 \%$

All included land was cultivated in 1982, is in a county for which rent data is available, and does not enter 1997 land uses: urban/built-up, water, or federal. Specifications control for 1997 land characteristics (prime farmland indicator, good land class indicator), 1996 land use rents and changes, 1996 demographics (population density, median household income, poverty rate, unemployment rate, percent black, percent white, median age, percent under 18, percent over 65), region code dummies, and land characteristic x rent interactions. Survey regressions performed with data points appropriately weighted and clustered errors. 
Table 5. Land Use Multinomial Logit Results

\begin{tabular}{|c|c|c|c|c|}
\hline Specification: & I & II & III & IV \\
\hline $\begin{array}{l}\text { What CRP land } \\
\text { included? }\end{array}$ & $\begin{array}{l}\text { Early signup } \\
\text { (CRP-Eligible) }\end{array}$ & $\begin{array}{c}\text { Early signup } \\
\text { (CRP-Eligible) }\end{array}$ & $\begin{array}{l}\text { Exit 1992-7 } \\
\text { (CRP-Exit) }\end{array}$ & $\begin{array}{l}\text { Exit 1992-7 } \\
\text { (CRP-Exit) }\end{array}$ \\
\hline $\begin{array}{l}\text { What non-CRP } \\
\text { (previously farmed) } \\
\text { land included? }\end{array}$ & $\begin{array}{c}\text { All land } \\
\text { (Control-All) }\end{array}$ & $\begin{array}{l}\text { Not farmed } \\
1992 \text { (Control- } \\
\text { Unfarmed) }\end{array}$ & $\begin{array}{c}\text { All land } \\
{\text { (Control-All })^{\mathrm{a}}}\end{array}$ & $\begin{array}{l}\text { Not farmed } \\
1992 \text { (Control- }^{\text {Unfarmed })^{\mathrm{a}}}\end{array}$ \\
\hline Cultivated cropland & $\begin{array}{c}-0.833^{* * * *} \\
(0.003)\end{array}$ & $\begin{array}{c}-0.256^{* * * *} \\
(0.008)\end{array}$ & $\begin{array}{c}-0.277 * * * \\
(0.008)\end{array}$ & $\begin{array}{c}0.262 * * * \\
(0.012)\end{array}$ \\
\hline Non-cultivated cropland & $\begin{array}{c}-0.020 * * * \\
(0.001)\end{array}$ & $\begin{array}{c}-0.247 * * * * \\
(0.007)\end{array}$ & $\begin{array}{c}0.058^{* * * *} \\
(0.004)\end{array}$ & $\begin{array}{c}-0.152 * * * \\
(0.008)\end{array}$ \\
\hline Pasture & $\begin{array}{c}0.001 \\
(0.001)\end{array}$ & $\begin{array}{c}-0.245^{* * * *} \\
(0.007)\end{array}$ & $\begin{array}{c}0.129 * * * \\
(0.006)\end{array}$ & $\begin{array}{c}-0.093^{* * * *} \\
(0.009)\end{array}$ \\
\hline CRP & $\begin{array}{c}0.847 * * * \\
(0.003)\end{array}$ & $\begin{array}{c}0.851 * * * \\
(0.003)\end{array}$ & N/A & N/A \\
\hline Other & $\begin{array}{c}0.004 * * * \\
(0.001)\end{array}$ & $\begin{array}{c}-0.1043 * * * \\
(0.004)\end{array}$ & $\begin{array}{c}0.091 * * * \\
(0.004)\end{array}$ & $\begin{array}{c}-0.018 * * * \\
(0.006)\end{array}$ \\
\hline$n$ (observations) & 165,188 & 25,652 & 155,888 & 17,308 \\
\hline$N$ (hundreds of acres) & $2,887,997$ & 399,719 & $2,712,792$ & 241,650 \\
\hline$F$ & $3,766.86$ & 1573.45 & 161.98 & 39.21 \\
\hline
\end{tabular}

$*$ significant at $10 \%, * *$ significant at $5 \%$; *** significant at $1 \%$

Cells show marginal effects of 1992 CRP status dummy on each land use. All included land was cultivated in 1982, is in a county for which rent data is available, and does not enter 1997 land uses: urban/built-up, water, or federal. Specifications control for 1997 land characteristics (prime farmland indicator, good land class indicator), 1996 land use rents and changes, 1996 demographics (population density, median household income, poverty rate, unemployment rate, percent black, percent white, median age, percent under 18, percent over 65), and region code dummies. Survey regressions performed with data points appropriately weighted and clustered errors.

${ }^{a}$ For these regressions only, both Control groups exclude land that becomes CRP in 1997 (0.67\% of Control-All and $0.53 \%$ of Control-Unfarmed). 
Table 6. Conservation Practice Results

\begin{tabular}{lcc}
\hline What CRP land included? & Specification I & Specification II \\
$\begin{array}{l}\text { What non-CRP (previously } \\
\text { farmed) land included? }\end{array}$ & $\begin{array}{c}\text { All land (Control-All) - } \\
\text { non-highly-erodible } \\
\text { non-highly-erodible }\end{array}$ & $\begin{array}{c}\text { Exit 1992-7 (CRP-Exit) - } \\
\text { non-highly-erodible } \\
\text { Not farmed 1992 } \\
\text { (Control-Unfarmed) - } \\
\text { non-highly-erodible }\end{array}$ \\
\hline OLS & 0.014 & $0.044^{* *}$ \\
Logit & $(0.019)$ & $(0.022)$ \\
& 0.020 & $0.040^{*}$ \\
Probit & $(0.024)$ & $(0.021)$ \\
& 0.020 & $0.041^{*}$ \\
$n$ (observations) & $(0.024)$ & $(0.022)$ \\
$N$ (hundreds of acres) & 101,572 & 2,386 \\
\hline
\end{tabular}

* significant at $10 \%, * *$ significant at $5 \%$; *** significant at $1 \%$

Only non-highly-erodible land included

Land was in the categories described in the text but only non-highly erodible (erodibility index of 8 or lower). All included land was cultivated in 1982, is in a county for which rent data is available, and does not enter 1997 land uses: urban/built-up, water, or federal. Specifications control for 1997 land characteristics (prime farmland indicator, good land class indicator, slope, and erodibility index), 1996 land use rents and changes, 1996 demographics (population density, median household income, poverty rate, unemployment rate, percent black, percent white, median age, percent under 18, percent over 65), region code dummies, and land characteristic $\mathrm{x}$ rent interactions. Survey regressions performed with data points appropriately weighted and clustered errors. 
Table A-1. Land Use Matching Results with Pre-Processed Samples

\begin{tabular}{lcccc}
\hline Specification: & I & II & III & IV \\
\hline What CRP land & Early signup & Early signup & Exit 1992-7 & Exit 1992-7 \\
included? & (CRP-Eligible) & (CRP-Eligible) & (CRP-Exit) & (CRP-Exit) \\
What non-CRP & All land & Not farmed & All land & Not farmed \\
(previously farmed) & (Control-All) & 1992 (Control- & (Control-All) & 1992 (Control- \\
land included? & & Unfarmed) & & Unfarmed) \\
\hline Matching (ATT) & $-0.702^{* * *}$ & $-0.167 * * *$ & $-0.322^{* * *}$ & $0.224^{* * * *}$ \\
& $(0.016)$ & $(0.017)$ & $(0.021)$ & $(0.022)$ \\
\hline OLS & $-0.777 * * *$ & $-0.191^{* * *}$ & $-0.316^{* * *}$ & $0.224^{* * *}$ \\
& $(0.003)$ & $(0.006)$ & $(0.007)$ & $(0.009)$ \\
Logit (marginal effect) & $-0.838^{* * *}$ & $-0.224^{* * *}$ & $-0.286^{* * *}$ & $0.268^{* * *}$ \\
& $(0.003)$ & $(0.007)$ & $(0.007)$ & $(0.012)$ \\
Probit (marginal effect) & $-0.827 * * *$ & $-0.229 * * *$ & $-0.303^{* * *}$ & $0.259^{* * * *}$ \\
& $(0.002)$ & $(0.007)$ & $(0.007)$ & $(0.011)$ \\
\hline$n$ (observations) & 165,188 & 25,652 & 156,919 & 17,383 \\
$N$ (hundreds of acres) & $2,887,997$ & 399,719 & $2,731,206$ & 242,928 \\
\hline
\end{tabular}

$*$ significant at $10 \%, * *$ significant at $5 \% ; * * *$ significant at $1 \%$

All included land was cultivated in 1982, is in a county for which rent data is available, and does not enter 1997 land uses: urban/built-up, water, or federal. Specifications control for 1997 land characteristics (prime farmland indicator, good land class indicator), 1996 land use rents and changes, 1996 demographics (population density, median household income, poverty rate, unemployment rate, percent black, percent white, median age, percent under 18, percent over 65), region code dummies, and land characteristic $\mathrm{x}$ rent interactions. Survey regressions performed with data points appropriately weighted and clustered errors. Matching uses Mahalanobis metric plus propensity score. 
Table A-2. Land Use Matching Robustness Checks for CRP-EXIT comparison to ControlUnfarmed

\begin{tabular}{|c|c|c|c|c|c|c|}
\hline Specification: & IV & IV-both-G & IV-both-P & IV-Ctrl-G & IV-Ctrl-P & IV-Ctrl-HEL \\
\hline $\begin{array}{l}\text { What CRP land } \\
\text { included? }\end{array}$ & $\begin{array}{l}\text { Exit 1992-7 } \\
\text { (CRP-Exit) }\end{array}$ & $\begin{array}{l}\text { Exit 1992-7 } \\
\text { (CRP-Exit)- } \\
\text { good land class }\end{array}$ & $\begin{array}{l}\text { Early signup } \\
\text { (CRP-Eligible) } \\
\text { - prime }\end{array}$ & $\begin{array}{l}\text { Exit 1992-7 } \\
\text { (CRP-Exit) }\end{array}$ & $\begin{array}{l}\text { Early signup } \\
\text { (CRP-Eligible) }\end{array}$ & $\begin{array}{l}\text { Exit 1992-7 } \\
\text { (CRP-Exit) }\end{array}$ \\
\hline $\begin{array}{l}\text { What non-CRP } \\
\text { (previously farmed) } \\
\text { land included? }\end{array}$ & $\begin{array}{l}\text { Not farmed } \\
1992 \text { (Control- } \\
\text { Unfarmed) }\end{array}$ & $\begin{array}{l}\text { Not farmed } 1992 \\
\text { (Control- } \\
\text { Unfarmed) - } \\
\text { good land class }\end{array}$ & $\begin{array}{l}\text { Not farmed } \\
1992 \text { (Control- } \\
\text { Unfarmed) - } \\
\text { prime }\end{array}$ & $\begin{array}{l}\text { Not farmed } 1992 \\
\text { (Control- } \\
\text { Unfarmed)- } \\
\text { good land class }\end{array}$ & $\begin{array}{l}\text { Not farmed } \\
1992 \text { (Control- } \\
\text { Unfarmed) - } \\
\text { prime }\end{array}$ & $\begin{array}{c}\text { Not farmed } \\
1992 \text { (Control- } \\
\text { Unfarmed) - } \\
\text { highly erodible }\end{array}$ \\
\hline Matching (ATT) & $\begin{array}{c}0.224 * * * \\
(0.022)\end{array}$ & $\begin{array}{c}0.209 * * * \\
(0.024)\end{array}$ & $\begin{array}{c}0.251 * * * \\
(0.035)\end{array}$ & $\begin{array}{c}0.208 * * * \\
(0.023)\end{array}$ & $\begin{array}{c}0.192 * * * \\
(0.029)\end{array}$ & $\begin{array}{l}0.331 * * \\
(0.019)\end{array}$ \\
\hline OLS & $\begin{array}{c}0.224 * * * \\
(0.009)\end{array}$ & $\begin{array}{c}0.242 * * * \\
(0.010)\end{array}$ & $\begin{array}{c}0.274 * * * \\
(0.016)\end{array}$ & $\begin{array}{c}0.235^{* * * *} \\
(0.010)\end{array}$ & $\begin{array}{c}0.257 * * * \\
(0.015)\end{array}$ & $\begin{array}{c}0.324 * * * \\
(0.010)\end{array}$ \\
\hline $\begin{array}{l}\text { Logit (marginal } \\
\text { effect) }\end{array}$ & $\begin{array}{c}0.268 * * * \\
(0.012)\end{array}$ & $\begin{array}{c}0.285 * * * \\
(0.013)\end{array}$ & $\begin{array}{c}0.333 * * * \\
(0.018)\end{array}$ & $\begin{array}{c}0.275 * * * \\
(0.013)\end{array}$ & $\begin{array}{c}0.312 * * * \\
(0.018)\end{array}$ & $\begin{array}{c}0.368 * * * \\
(0.013)\end{array}$ \\
\hline $\begin{array}{l}\text { Probit (marginal } \\
\text { effect) }\end{array}$ & $\begin{array}{c}0.259 * * * \\
(0.011)\end{array}$ & $\begin{array}{c}0.276 * * * \\
(0.012)\end{array}$ & $\begin{array}{c}0.318 * * * \\
(0.018)\end{array}$ & $\begin{array}{c}0.267 * * * \\
(0.012)\end{array}$ & $\begin{array}{c}0.299 * * * \\
(0.017)\end{array}$ & $\begin{array}{c}0.365 * * * \\
(0.012)\end{array}$ \\
\hline $\begin{array}{l}n \text { (data points) } \\
N \text { (hundreds of acres) }\end{array}$ & $\begin{array}{c}17,383 \\
242,928\end{array}$ & $\begin{array}{c}15,625 \\
217,165\end{array}$ & $\begin{array}{c}7,796 \\
103,535\end{array}$ & $\begin{array}{c}15,862 \\
220,690\end{array}$ & $\begin{array}{c}9,326 \\
124,105\end{array}$ & $\begin{array}{c}13,300 \\
175,138\end{array}$ \\
\hline
\end{tabular}

* significant at $10 \%$, ** significant at 5\%; *** significant at $1 \%$

All included land was cultivated in 1982, is in a county for which rent data is available, and does not enter 1997 land uses: urban/built-up, water, or federal. Specifications control for 1997 land characteristics (prime farmland indicator, good land class indicator), 1996 land use rents and changes, 1996 demographics (population density, median household income, poverty rate, unemployment rate, percent black, percent white, median age, percent under 18, percent over 65), region code dummies, and land characteristic $\mathrm{x}$ rent interactions. Survey regressions performed with data points appropriately weighted and clustered errors. Matching uses Mahalanobis metric plus propensity score. 
Table A-3. Conservation Practice Matching Results

\begin{tabular}{|c|c|c|}
\hline & Specification I & Specification II \\
\hline What CRP land included? & $\begin{array}{l}\text { Exit 1992-7 (CRP-Exit) - } \\
\text { non-highly-erodible }\end{array}$ & $\begin{array}{l}\text { Exit 1992-7 (CRP-Exit) - } \\
\text { non-highly-erodible }\end{array}$ \\
\hline $\begin{array}{l}\text { What non-CRP (previously } \\
\text { farmed) land included? }\end{array}$ & $\begin{array}{l}\text { All land (Control-All) - } \\
\text { non-highly-erodible }\end{array}$ & $\begin{array}{c}\text { Not farmed } 1992 \\
\text { (Control-Unfarmed) - } \\
\text { non-highly-erodible }\end{array}$ \\
\hline Matching & $\begin{array}{l}-0.002 \\
(0.027)\end{array}$ & $\begin{array}{l}0.064 * * \\
(0.031)\end{array}$ \\
\hline OLS & $\begin{array}{c}0.014 \\
(0.019)\end{array}$ & $\begin{array}{l}0.044 * * \\
(0.022)\end{array}$ \\
\hline Logit & $\begin{array}{c}0.020 \\
(0.024)\end{array}$ & $\begin{array}{l}0.040 * \\
(0.021)\end{array}$ \\
\hline Probit & $\begin{array}{c}0.020 \\
(0.024)\end{array}$ & $\begin{array}{l}0.041^{*} \\
(0.022)\end{array}$ \\
\hline$n$ (observations) & 101,572 & 2,386 \\
\hline$N$ (hundreds of acres) & $1,778,572$ & 37,181 \\
\hline
\end{tabular}

$*$ significant at $10 \%, * *$ significant at $5 \%$; *** significant at $1 \%$

Only non-highly-erodible land included

Land was in the categories described in the text but only non-highly erodible (erodibility index of 8 or lower). All included land was cultivated in 1982, is in a county for which rent data is available, and does not enter 1997 land uses: urban/built-up, water, or federal. Specifications control for 1997 land characteristics (prime farmland indicator, good land class indicator, slope, and erodibility index), 1996 land use rents and changes, 1996 demographics (population density, median household income, poverty rate, unemployment rate, percent black, percent white, median age, percent under 18, percent over 65), region code dummies, and land characteristic x rent interactions. Survey regressions performed with data points appropriately weighted and clustered errors. Matching uses Mahalanobis metric plus propensity score. 